
\title{
BResarch Soutere \\ Van der Pol Model in Two-Delay Differential Equation Representation
}

\section{A. Elfouly ( $\square$ maf080877@yahoo.com )}

Mansoura University

\section{A. Sohaly}

Mansoura University

\section{Research Article}

Keywords: Parkinson's disease, damped harmonic oscillator, Van der Pol equation, Delay differential equation

Posted Date: August 26th, 2021

DOl: https://doi.org/10.21203/rs.3.rs-828074/v1

License: (c) (1) This work is licensed under a Creative Commons Attribution 4.0 International License. Read Full License

Version of Record: A version of this preprint was published at Scientific Reports on February 21st, 2022. See the published version at https://doi.org/10.1038/s41598-022-06911-3. 


\title{
Van der Pol Model in Two-Delay Differential Equation Representation
}

\author{
M. A. Elfouly*, M. A. Sohaly \\ Department of Mathematics - Faculty of Science, Mansoura University -Egypt \\ maf080877@yahoo.com,m_stat2000@yahoo.com
}

\section{$\underline{\text { Abstract }}$}

The Van der Pol equation is the mathematical model of a second-order ordinary differential equation with cubic nonlinearity. In this paper, the differential equation of the Van der Pol model and RLC (resistor - inductor-capacitor) circuit are deduced from a delay differential equation. The Van der Pol delay model contains two delays, which opens the way for the reuse of its applications. Also, the model for Parkinson's disease modification is described as the Van der Pol model.

Keywords: Parkinson's disease, damped harmonic oscillator, Van der Pol equation, Delay

\section{Introduction} differential equation.

The Van der Pol oscillator is a classic example of self-oscillatory system and is now considered as very useful mathematical model that can be used in much more complicated and modified systems. RLC circuit is an electrical circuit consisting of a resistor (R), an inductor (L), and a capacitor (C), ordinary differential equation (ODE) that expresses the LRC circuit if they are connected in series as damped harmonic oscillator:

$$
\frac{\mathrm{d}^{2} \mathrm{x}}{\mathrm{dt}^{2}}+\mu \frac{\mathrm{dx}}{\mathrm{dt}}+\beta \mathrm{x}=0
$$

In the 1920's by Balthazar van der Pol, this circuit is an RLC loop, but with the passive resistor of Ohm's Law replaced by triode [1], the Dutch engineer Balthazar van der Pol presented a mathematical model to describe oscillations in electrical circuits. Balthazar van der Pol used ordinary differential equation as follows:

$$
\frac{\mathrm{d}^{2} \mathrm{x}}{\mathrm{dt}^{2}}+\mu\left(\mathrm{x}^{2}-1\right) \frac{\mathrm{dx}}{\mathrm{dt}}+\beta \mathrm{x}=0
$$

Van der Pol is now regarded as the fundamental oscillation model in physical, electronic, biological, neurological, sociological, and economic terms [2]. Parkinson's disease was studied mathematically by G. Austin in 1961 and expressed the amplitude of hand tremor by a second-order differential equation, using the Van der Pol model [3] in (2). Claudia (2009) expresses another symptom using nonlinear two-delay differential equation in [4] as follows:

$$
\frac{d x}{d t}=a_{1} x\left(t-\tau_{1}\right)+a_{2} x\left(t-\tau_{2}\right)+a_{3} x\left(t-\tau_{1}\right) x\left(t-\tau_{2}\right)
$$

The associated linear model for (3) is

$$
\frac{d x}{d t}=a_{1} x\left(t-\tau_{1}\right)+a_{2} x\left(t-\tau_{2}\right)
$$

* Corresponding author.E-mail addresses: maf080877@yahoo.com (M. A. Elfouly) 
In this paper, we derive the Van der Pol equation as a two-delay differential equation. We deduce the Van der Pol equation from the equation derived using Taylor series in the case of small delays. We use the deduced equation as a mathematical model for Parkinson's disease. We give some numerical studies that show the deduced equation expresses some cases of the Van der Pol equation, such as relaxation and oscillation.

\section{Represented RLC circuit as two-delay differential equation}

In AC circuits with a capacitor the equation of the current intensity I curve [5] is given as:

$$
I=I_{\max } \cos (2 \pi f t)
$$

where, $f$ is the frequency, by differentiating with respect to time:

$$
\begin{aligned}
& \frac{\mathrm{dI}}{\mathrm{dt}}=-2 \pi f \mathrm{I}_{\max } \sin (2 \pi f \mathrm{t}) \\
& \frac{\mathrm{dI}}{\mathrm{dt}}=-2 \pi f \mathrm{I}_{\max } \cos \left(2 \pi f\left(\mathrm{t}-\frac{1}{4 \mathrm{f}}\right)\right) \\
& \left.\frac{\mathrm{dI}}{\mathrm{dt}}=-2 \pi \mathrm{fI}\left(\mathrm{t}-\tau_{1}\right)\right)
\end{aligned}
$$

In AC circuits with an inductor the equation of the current intensity I curve [5] is given as:

$$
I=I_{\max } \sin (2 \pi f t)
$$

where, $\mathrm{f}$ is the frequency, by differentiating with respect to time

$$
\begin{aligned}
& \frac{\mathrm{dI}}{\mathrm{dt}}=2 \pi f \mathrm{I}_{\max } \cos (2 \pi f \mathrm{t}) \\
& \frac{\mathrm{dI}}{\mathrm{dt}}=2 \pi f \mathrm{I}_{\max } \cos \left(2 \pi f\left(t-\frac{3}{4 f}\right)\right) \\
& \left.\frac{\mathrm{dI}}{\mathrm{dt}}=2 \pi f \mathrm{I}\left(\mathrm{t}-\tau_{2}\right)\right)
\end{aligned}
$$

where, $\tau_{1}=\frac{1}{4 \mathrm{f}}$ and $\tau_{2}=\frac{3}{4 \mathrm{f}}$ are the time delays, then the model (4) is the delay differential equation for the RLC circuit.

Using Taylor series for small delays, the equation (4) can be written as follows:

$$
\begin{gathered}
\frac{\mathrm{dx}}{\mathrm{dt}}=\mathrm{a}_{1}\left(\mathrm{x}-\tau_{1} \frac{\mathrm{dx}}{\mathrm{dt}}+\frac{\tau_{1}^{2}}{2} \frac{\mathrm{d}^{2} \mathrm{x}}{\mathrm{d}^{2} \mathrm{t}}+\ldots\right)+\mathrm{a}_{2}\left(\mathrm{x}-\tau_{2} \frac{\mathrm{dx}}{\mathrm{dt}}+\frac{\tau_{2}^{2}}{2} \frac{\mathrm{d}^{2} \mathrm{x}}{\mathrm{d}^{2} \mathrm{t}}+\ldots\right) \\
\left(\frac{\mathrm{a}_{1} \tau_{1}^{2}}{2}+\frac{\mathrm{a}_{2} \tau_{2}^{2}}{2}\right) \frac{\mathrm{d}^{2} \mathrm{x}}{\mathrm{d}^{2} \mathrm{t}}+\left(-\mathrm{a}_{1} \tau_{1}-\mathrm{a}_{2} \tau_{2}-1\right) \frac{\mathrm{dx}}{\mathrm{dt}}+\left(\mathrm{a}_{1}+\mathrm{a}_{2}\right) \mathrm{x}=0 \\
\frac{\mathrm{d}^{2} \mathrm{x}}{\mathrm{d}^{2} \mathrm{t}}-\frac{2\left(1+\mathrm{a}_{1} \tau_{1}+\mathrm{a}_{2} \tau_{2}\right)}{\mathrm{a}_{1} \tau_{1}^{2}+\mathrm{a}_{2} \tau_{2}^{2}} \frac{\mathrm{dx}}{\mathrm{dt}}+\frac{2\left(\mathrm{a}_{1}+\mathrm{a}_{2}\right)}{\mathrm{a}_{1} \tau_{1}^{2}+\mathrm{a}_{2} \tau_{2}^{2}} \mathrm{x}=0 \\
\text { If } \mu=-\frac{2\left(1+\mathrm{a}_{1} \tau_{1}+\mathrm{a}_{2} \tau_{2}\right)}{\mathrm{a}_{1} \tau_{1}^{2}+\mathrm{a}_{2} \tau_{2}^{2}} \text { and } \quad \beta=\frac{2\left(\mathrm{a}_{1}+\mathrm{a}_{2}\right)}{\mathrm{a}_{1} \tau_{1}^{2}+\mathrm{a}_{2} \tau_{2}^{2}}
\end{gathered}
$$

Then we get the model (1)

\section{Stability analysis for the model in (4)}

By substituting in (4) as $\mathrm{x}(\mathrm{t})=\mathrm{e}^{-\lambda \tau}$, then the characteristic equation is given as follow:

$$
\lambda=\mathrm{a}_{1} \mathrm{e}^{-\lambda \tau_{1}}+\mathrm{a}_{2} \mathrm{e}^{-\lambda \tau_{2}}
$$

For small delays $\tau_{1}<<1, \tau_{2}<<1$

$$
\lambda=\mathrm{a}_{1}+\mathrm{a}_{2}
$$


Then the fixed point $x^{*}=0$ is asymptotically stable if,

$$
a_{1}+a_{2}<0
$$

For damped harmonic oscillator the characteristic for model (1):

$$
\lambda^{2}+\mu \lambda+\beta=0
$$

which has the solutions,

$$
\lambda=\frac{-\mu}{2} \pm \sqrt{\left(\frac{\mu}{2}\right)^{2}-\beta}
$$

The fixed point $x^{*}=0$ is asymptotically stable if $\mu>0$ and $\beta>0$ [6] i.e., the condition

$$
\text { is: } \quad \frac{1+\mathrm{a}_{1} \tau_{1}+\mathrm{a}_{2} \tau_{2}}{\mathrm{a}_{1} \tau_{1}^{2}+\mathrm{a}_{2} \tau_{2}^{2}}<0
$$

\section{Represented Van der Pol equation}

In the case of replacing resistance in an LRC circuit by a triode, the rate of change of current depends on the difference between $\mathrm{x}\left(\mathrm{t}-\tau_{1}\right)-\mathrm{x}\left(\mathrm{t}-\tau_{2}\right)$.

The current of the anode is the difference between the cathode current and a grid current. From the special curves of the tripod, there is a phase difference between them and this amount can be multiplied by the square of the current because the relationship is non-linear [2].

Thus, we get the following form:

$$
\frac{d x(t)}{d t}=a_{1} x\left(t-\tau_{1}\right)+a_{2} x\left(t-\tau_{2}\right)-(x(t))^{2}\left(x\left(t-\tau_{2}\right)-x\left(t-\tau_{1}\right)\right)
$$

Using Taylor series for small delays and mean value theory, the equation (9) can be written as follows:

$$
\begin{aligned}
& \frac{\mathrm{dx}}{\mathrm{dt}}=\mathrm{a}_{1}\left(\mathrm{x}-\tau_{1} \frac{\mathrm{dx}}{\mathrm{dt}}+\frac{\tau_{1}^{2}}{2} \frac{\mathrm{d}^{2} \mathrm{x}}{\mathrm{d}^{2} \mathrm{t}}+\ldots\right)+\mathrm{a}_{2}\left(\mathrm{x}-\tau_{2} \frac{\mathrm{dx}}{\mathrm{dt}}+\frac{\tau_{2}^{2}}{2} \frac{\mathrm{d}^{2} \mathrm{x}}{\mathrm{d}^{2} \mathrm{t}}+\ldots\right)+\left(\tau_{2}-\tau_{1}\right) \mathrm{x}^{2} \frac{\mathrm{dx}}{\mathrm{dt}} \\
& \left(\frac{\mathrm{a}_{1} \tau_{1}^{2}}{2}+\frac{\mathrm{a}_{2} \tau_{2}^{2}}{2}\right) \frac{\mathrm{d}^{2} \mathrm{x}}{\mathrm{d}^{2} \mathrm{t}}+\left(-\mathrm{a}_{1} \tau_{1}-\mathrm{a}_{2} \tau_{2}+\left(\tau_{2}-\tau_{1}\right) \mathrm{x}^{2}-1\right) \frac{\mathrm{dx}}{\mathrm{dt}}+\left(\mathrm{a}_{1}+\mathrm{a}_{2}\right) \mathrm{x}=0 \\
& \frac{\mathrm{d}^{2} \mathrm{x}}{\mathrm{d}^{2} \mathrm{t}}+\frac{2\left(\tau_{2}-\tau_{1}\right)}{\mathrm{a}_{1} \tau_{1}^{2}+\mathrm{a}_{2} \tau_{2}^{2}}\left(\mathrm{x}^{2}-\frac{1+\mathrm{a}_{1} \tau_{1}+\mathrm{a}_{2} \tau_{2}}{\tau_{2}-\tau_{1}}\right) \frac{\mathrm{dx}}{\mathrm{dt}}+\frac{2\left(\mathrm{a}_{1}+\mathrm{a}_{2}\right)}{\mathrm{a}_{1} \tau_{1}^{2}+\mathrm{a}_{2} \tau_{2}^{2}} \mathrm{x}=0 \\
& \text { If } \alpha=\frac{1+\mathrm{a}_{1} \tau_{1}+\mathrm{a}_{2} \tau_{2}}{\tau_{2}-\tau_{1}}, \mu=\frac{2\left(\tau_{2}-\tau_{1}\right)}{\mathrm{a}_{1} \tau_{1}^{2}+\mathrm{a}_{2} \tau_{2}^{2}} \text { and } \beta=\frac{2\left(\mathrm{a}_{1}+\mathrm{a}_{2}\right)}{\mathrm{a}_{1} \tau_{1}^{2}+\mathrm{a}_{2} \tau_{2}^{2}}
\end{aligned}
$$

Then,

$$
\frac{d^{2} x(t)}{d^{2} t}+\mu\left(x^{2}-\alpha\right) \frac{d x(t)}{d t}+\beta x=0
$$

Equation (12) is the Van der Pol equation. In general, the Van der Pol equation can be written as a delay differential equation with two small delays as follows:

$$
\frac{d x(t)}{d t}=a_{1} x\left(t-\tau_{1}\right)+a_{2} x\left(t-\tau_{2}\right)-(x(t))^{2}\left(x\left(t-\tau_{2}\right)-x\left(t-\tau_{1}\right)\right)
$$

where $\mathrm{a}_{1}$ and $\mathrm{a}_{2}$ are scalar parameters.

For zero fixed point, the associated linear model for (27) is the model in (4). Then the fixed point $\mathrm{x}^{*}=0$ is asymptotically stable if, $\mathrm{a}_{1}+\mathrm{a}_{2}<0$. 
The model in (1) can be linearized for zero fixed point as follows [6]:

$$
\begin{aligned}
& \&=y \\
& \&=\mu y-\beta x
\end{aligned}
$$

The fixed point $x^{*}=0$ is asymptotically stable if $\mu=\frac{2\left(\tau_{2}-\tau_{1}\right)}{a_{1} \tau_{1}^{2}+a_{2} \tau_{2}^{2}}<0$ [7], since $2\left(\tau_{2}-\tau_{1}\right)>0$, then fixed point $x^{*}=0$ is asymptotically stable if

$$
\mathrm{a}_{1} \tau_{1}^{2}+\mathrm{a}_{2} \tau_{2}^{2}<0
$$

\section{Parkinson's disease application}

The model in (4) and (27) can be presented as a model for Parkinson's disease, From Austin's results, $a_{1}$ and $a_{2}$ represents negative or positive feedback which work to reduce or increase symptoms. Due to the inconsistency of drug-blood-brain barrier crossing, Parkinson's disease patients have medication side effects, which can lead to more involuntary movements and a movement disorder. [7], in this case $a_{1}>0$ and $a_{2}>0$. In the case of positive feedback, $a_{1}+a_{2}>0$

The linear model in (4) is unstable; this is not compatible with biological systems. So we suggest general model written as follows:

$$
\frac{d x(t)}{d t}=a_{1} x\left(t-\tau_{1}\right)+a_{2} x\left(t-\tau_{2}\right)-(x(t))^{2}\left(b_{2} x\left(t-\tau_{2}\right)+b_{1} x\left(t-\tau_{1}\right)\right)
$$

where $a_{1}, a_{2}, b_{1}$ and $b_{2}$ are scalar parameters, $b_{1} b_{2}<0$ and $\left|b_{1}\right| \rightarrow\left|b_{2}\right|$.

In this model there are two fixed points zero fixed point and non-zero fixed point $x^{*}=\sqrt{\frac{a_{1}+a_{2}}{b_{1}+b_{2}}}$, where $\frac{a_{1}+a_{2}}{b_{1}+b_{2}}>0$.

For non-zero fixed point the associated linear model for (31) is

$$
\frac{\mathrm{dx}(\mathrm{t})}{\mathrm{dt}}=\delta \mathrm{x}\left(\mathrm{t}-\tau_{1}\right)-\delta \mathrm{x}\left(\mathrm{t}-\tau_{2}\right)-2\left(\mathrm{a}_{1}+\mathrm{a}_{2}\right) \mathrm{x}(\mathrm{t})
$$

where $\delta=\frac{a_{1} b_{2}-a_{2} b_{1}}{b_{2}-1}$

Characteristic equation is given by

$$
\lambda=\delta \mathrm{e}^{-\lambda \tau_{1}}-\delta \mathrm{e}^{-\lambda \tau_{2}}-2\left(\mathrm{a}_{1}+\mathrm{a}_{2}\right)
$$

For negative $\lambda$ and delays $\tau_{2}>\tau_{1}$

$$
\lambda=-2\left(a_{1}+a_{2}\right)
$$

Then non-zero fixed point $x^{*}=\sqrt{\frac{a_{1}+a_{2}}{b_{1}+b_{2}}}$ is asymptotically stable if,

$$
a_{1}+a_{2}>0
$$

If the negative feedback is greater than the positive feedback, then symptoms will end. If the positive feedback is greater than the negative feedback, then symptoms will not disappear, but will stabilize at the non-zero stability point.

\section{Numerical Cases Studies}




\section{Case 1:}

$\frac{d x}{d t}=-10 x(t-0.2)+3 x(t-0.3)$, where $x(t)=2$ for $t \leq 0$
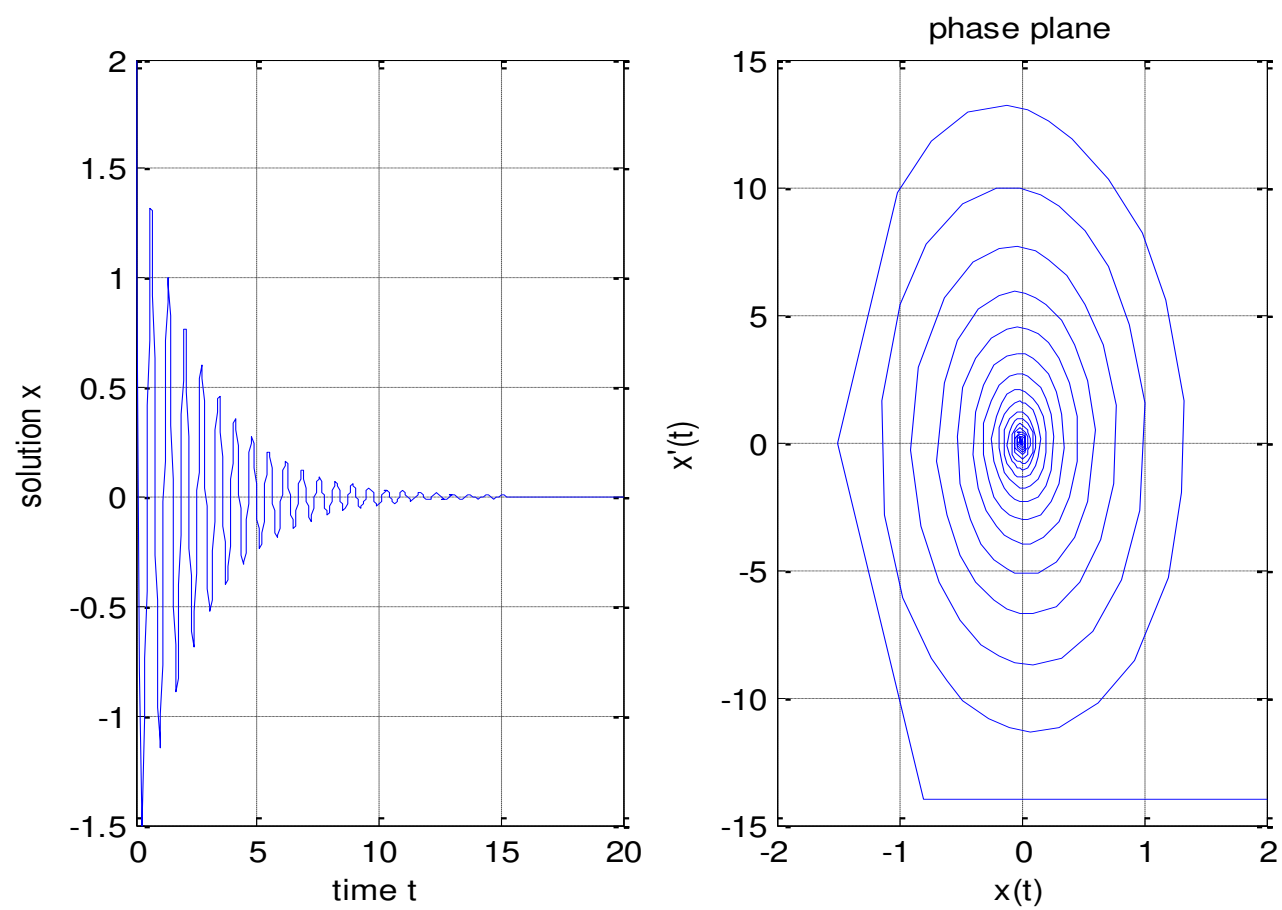

Fig. (1): Model (4) is stable and stability condition $a_{1}+a_{2}<0$ satisfied.
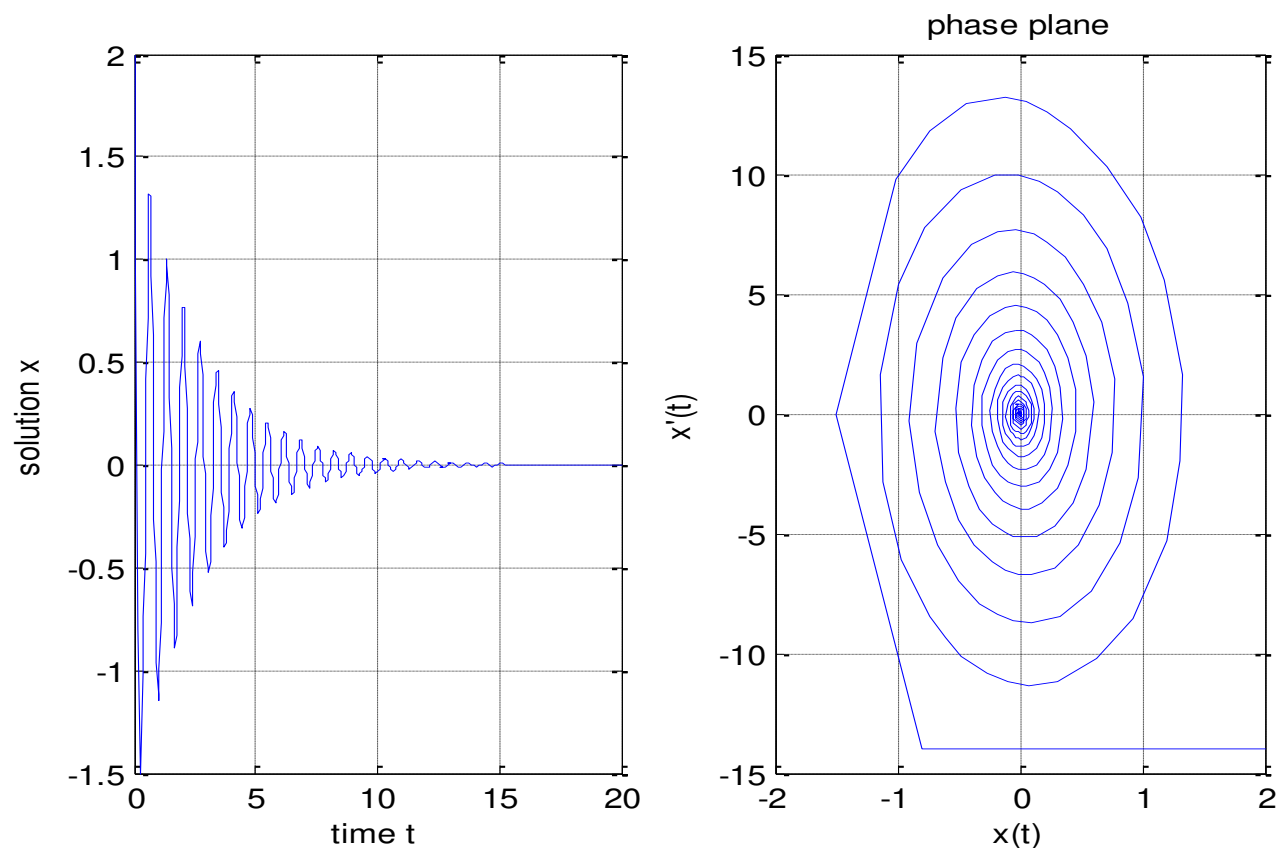

Fig. (2): Correspondence damped harmonic oscillator $\mu=1.53$ and $\beta=107.69$. 


\section{Case 2:}

$\frac{\mathrm{dx}}{\mathrm{dt}}=-7 \mathrm{x}\left(\mathrm{t}-\frac{\pi}{20}\right)+3 \mathrm{x}\left(\mathrm{t}-\frac{3 \pi}{20}\right)$, where $\mathrm{x}(\mathrm{t})=2$ for $\mathrm{t} \leq 0$
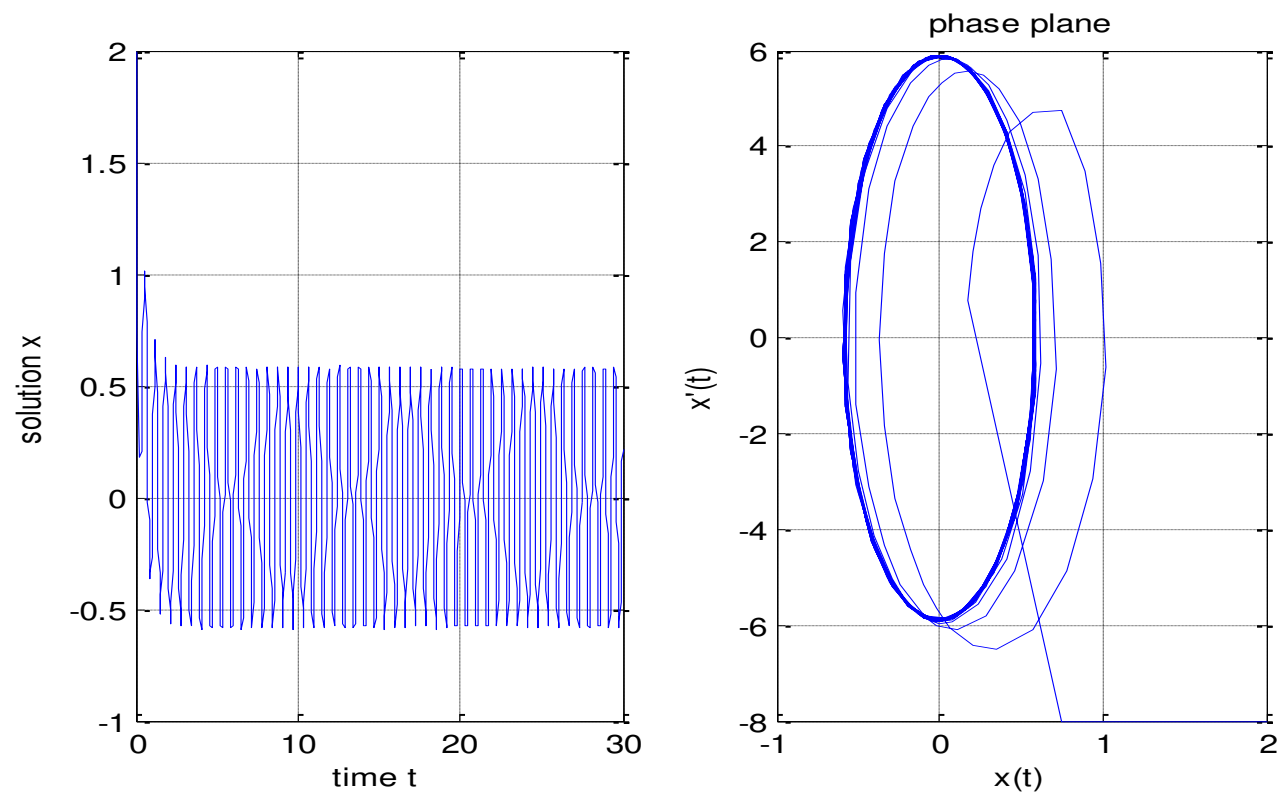

Fig. (3): Limit cyclic for Eq. (4).

\section{Case 3:}

$\frac{\mathrm{dx}}{\mathrm{dt}}=-0.9 \mathrm{x}\left(\mathrm{t}-\frac{\pi}{2}\right)+0.2 \mathrm{x}\left(\mathrm{t}-\frac{3 \pi}{2}\right)-\mathrm{x}^{2}\left[\mathrm{x}\left(\mathrm{t}-\frac{3 \pi}{2}\right)-\mathrm{x}\left(\mathrm{t}-\frac{\pi}{2}\right)\right]$, where $\mathrm{x}(\mathrm{t})=0.4$ for $\mathrm{t} \leq 0$
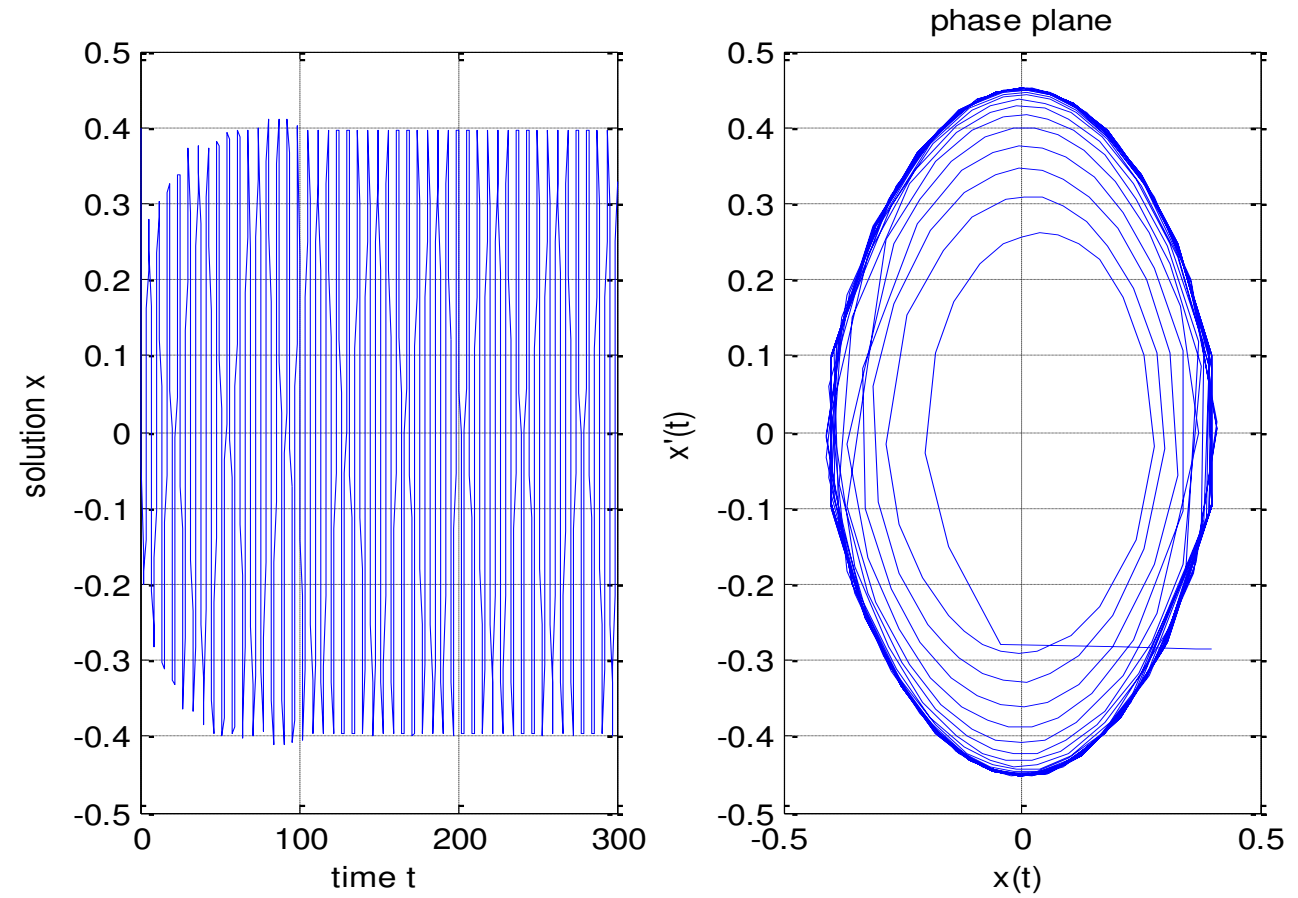

Fig. (4): Limit cyclic for Eq. (22). 


\section{Case 4:}
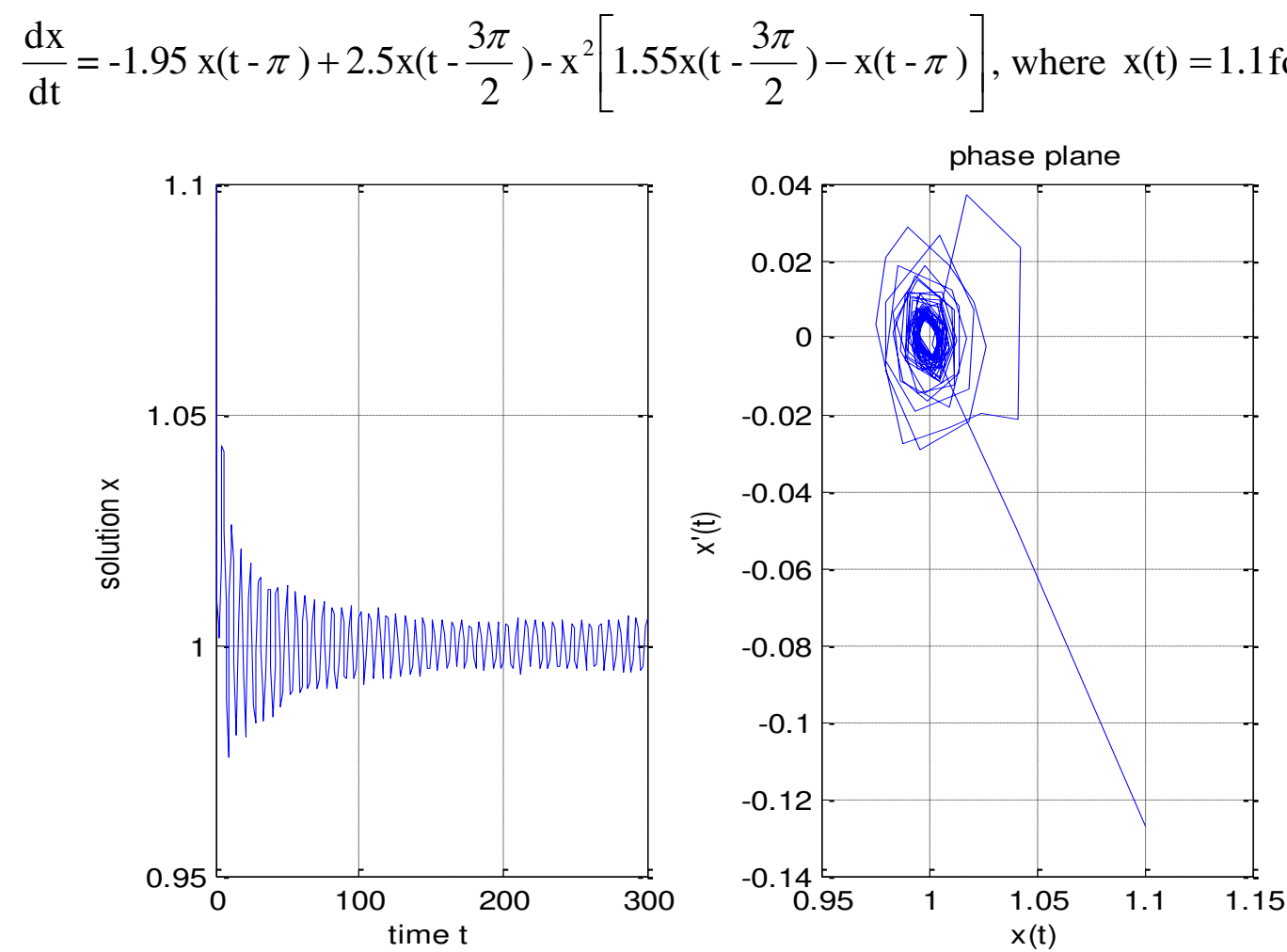

Fig. (5): Limit cyclic for Eq. (31).

\section{Case 5:}

$\frac{d x}{d t}=-8 x(t-0.1)+4 x(t-5)-x^{2}[x(t-5)-x(t-0.1)]$, where $x(t)=2$ for $t \leq 0$
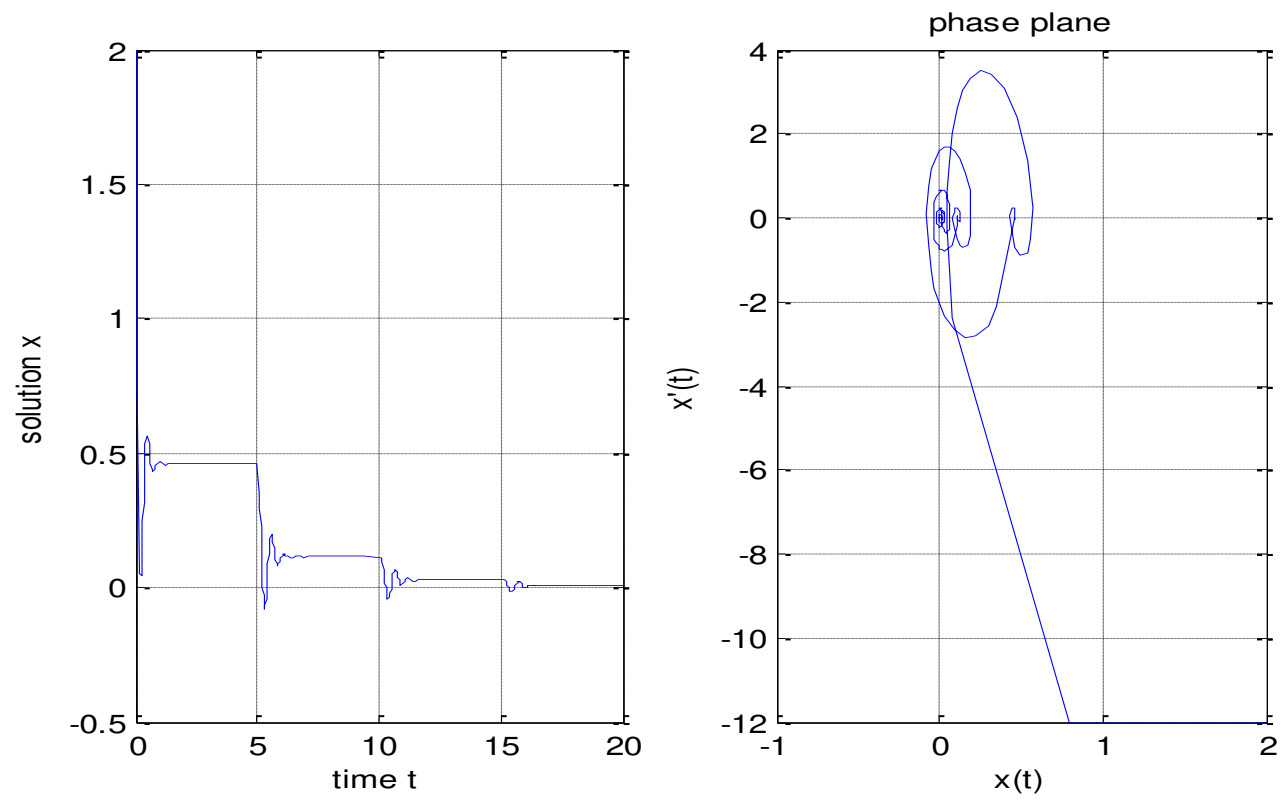

Fig. (6): Small delay and large delay. 


\section{Case 6:}

$\frac{d x}{d t}=-14 x(t-0.1)+2 x(t-5)-x^{2}[x(t-0.1)-x(t-5)]$, where $x(t)=2$ for $t \leq 0$
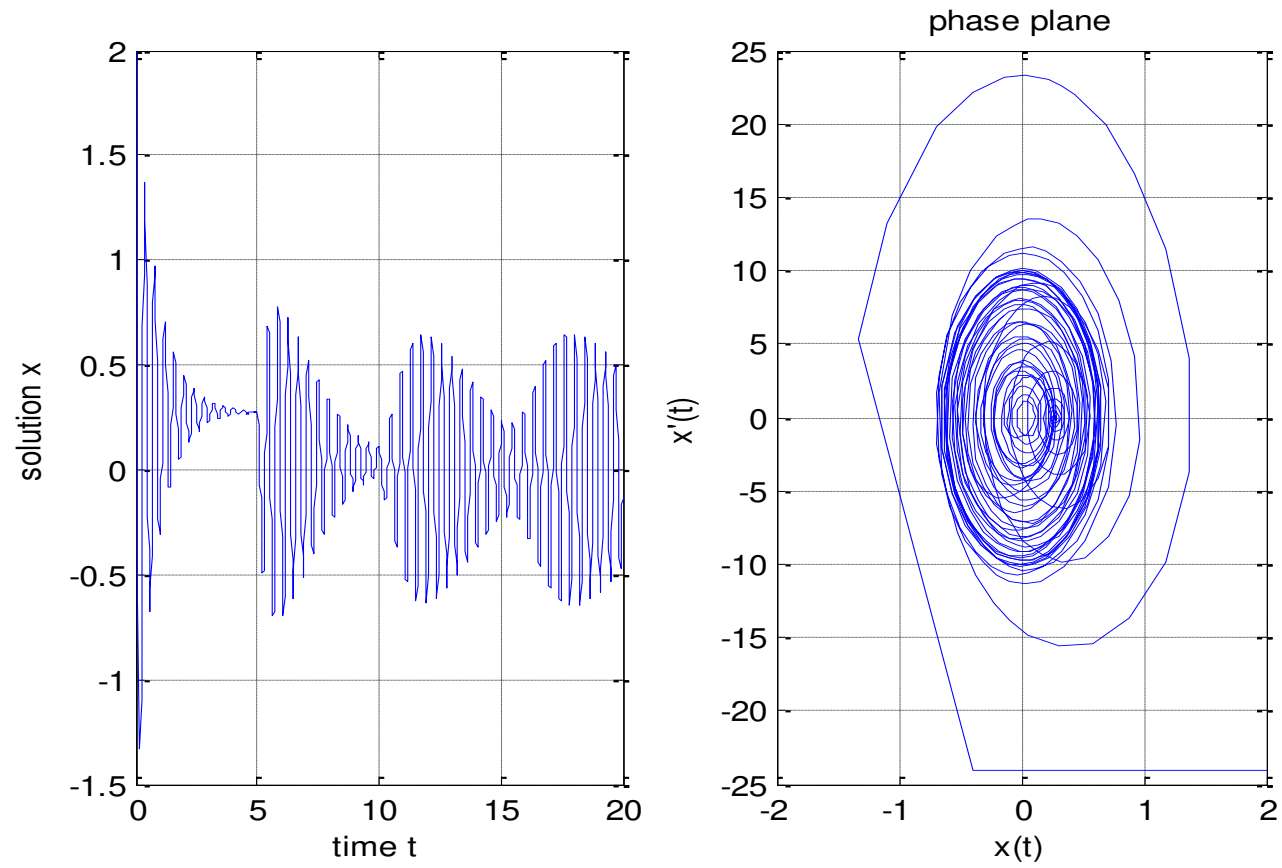

Fig. (7): Small delay and large delay.

\section{Case 7:}

$\frac{d x}{d t}=3 x(t-0.1)-4 x(t-5)+x^{2}[x(t-5)-x(t-0.1)]$, where $x(t)=2$ for $t \leq 0$
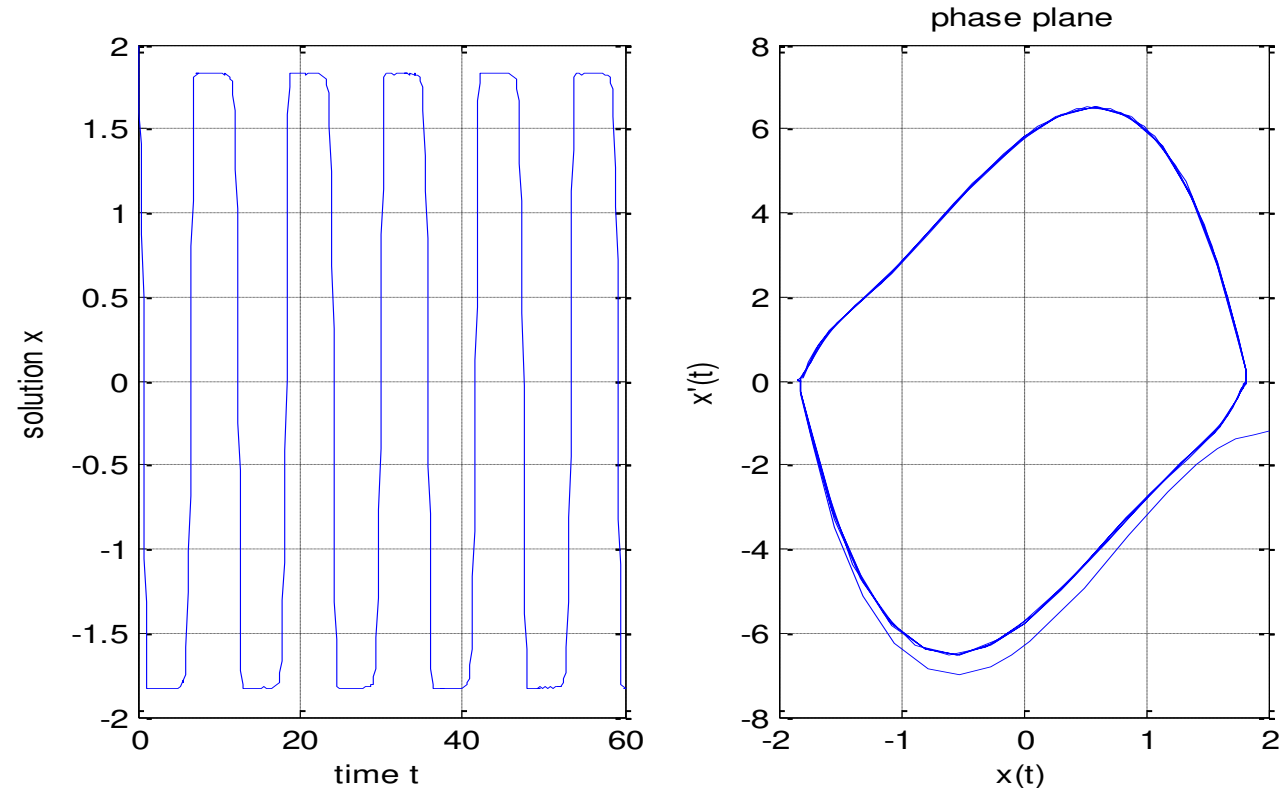

Fig. (8): Relaxation oscillation. 


\section{Conclusion}

Van der Pol model has many applications, especially neurological applications. Van der Pol model is used to describe the defects in Parkinson's disease, and a mathematical model for this disease is made using the delay differential equations in [4].

From the results of the study by G. Austin in [3], there are factors that work to reduce the defect, and thus act as negative feedback, and other factors that increase the defect and thus act as positive feedback. The model can then be assumed using the linear delay differential equations in (4), which $\mathrm{a}_{1}$ act as negative feedback for control on delay time $\tau_{1}$ and $\mathrm{a}_{2}$ act as positive feedback for control off delay time $\tau_{2}$.

In this paper, the differential equation of the Van der Pol model is deduced from a delay differential equation with two small delays, which opens the way for the re-use of the applications of the Van der Pol model by using differential equations with two delays.

In Parkinson's disease, the side effects of medication appear after a period of time, by giving them, and the patient's response to treatment decreases, and it may work to increase motor symptoms. A model has been modified to comply in this case.

Some numerical cases of the LRC circuit model have been simulated. See Fig. (1-3). Van der Pol model has been simulated. See Fig. (4-8), limit cyclic appears in Fig. (3-5), relaxation oscillation appears in Fig. (7-8), the effect of the non-linear part appears whenever the coefficients of the linear part are small. In the case of a small delay and a large delay, a repetition occurs and a relaxation oscillation occurs.

The proposed equation (31) is more dynamic and comprehensive and needs another study into the conditions of chaos, if any, and the conditions for Hopf bifurcation.

\section{References}

[1] Van der Pol, B., 1920. theory of the amplitude of frfeE. forced triode vibrations. Radio review, 1, pp.701-710.

[2] Tsatsos, M., 2008. the Van der Pol equation. arXiv preprint arXiv:0803.1658.

[3] Austin, G. and Tsai, C., 1962. A physiological basis and development of a model for parkinsonian tremor. Stereotactic and Functional Neurosurgery, 22(3-5), pp.248-258.

[4] Lainscsek, C., Schettino, L., Rowat, P., van Erp, E., Song, D. and Poizner, H., 2009. Nonlinear DDE analysis of repetitive hand movements in Parkinson's disease. In Applications of Nonlinear Dynamics (pp. 421-425). Springer, Berlin, Heidelberg.

[5] Charles, K.A. and Matthew, N.O., 2017. Fundamentals of electric circuits. McGrawhill Education.

[6] Agarwal, R.P., Hodis, S. and O'Regan, D., 2019. 500 Examples and Problems of Applied Differential Equations (pp. 163-182). Springer.

[7] Stoker, T.B. and Greenland, J.C., 2018. Parkinson's Disease: Pathogenesis and Clinical Aspects. 